\title{
Application of dietetics in reproductive medicine
}

\author{
Michal Skrzypek ${ }^{1, A-F}$, Artur Wdowiak ${ }^{2, A-F}$, Agnieszka Marzec ${ }^{1, B-E}$ \\ ${ }^{1}$ Department of Clinical Dietetics, Faculty of Health Sciences, Medical University, Lublin, Poland \\ ${ }^{2}$ Diagnostic Techniques Unit, Faculty of Health Sciences, Medical University, Lublin, Poland \\ A - Research concept and design, B - Collection and/or assembly of data, C - Data analysis and interpretation, \\ $D$ - Writing the article, E-Critical revision of the article, F- Final approval of article
}

Skrzypek M, Wdowiak A, Marzec A. Application of dietetics in reproductive medicine. Ann Agric Environ Med. 2017 ; $24(4)$ : 559-565. doi: $10.26444 /$ aaem/76997

\begin{abstract}
In the light of up-to-date epidemiological data concerning the prevalence of infertility, and also considering the scale of the problem of obesity and proven cause-effect relationship between abnormal body weight and infertility, it is justifiable to undertake the task of systematization of the state of knowledge concerning nutritional correlates of infertility, in order to create a scientific basis for the formulation of the assumptions of a fertility diet. The study is an attempt to systematize the current state of knowledge concerning the importance of energy and structural (qualitative) aspects of nutrition in the prevention and treatment of infertility.
\end{abstract}

\section{Key words}

Infertility, human reproductive function, nutritional status, overweight, obesity, fertility diet

\section{INTRODUCTION}

The systematization of the state of knowledge concerning the effect of energy and qualitative aspects of nutrition on fertility is important considering the prevalence of obesity and infertility in the societies of Western countries. In 2014, on the world scale, more than 1.9 billion people aged over 18 were overweight, including over 600 million suffering from obesity [1]. In that year, obesity concerned $13 \%$ of the adult world population, and overweight $-39 \%$, whereas the prevalence of obesity during the period 1980-2014 more than doubled [1]. The problem of overweight or obesity concerns more than a half of the women at reproductive age, and implies an increased risk of infertility and obstetric complications [2]. This is also related with an increased infertility risk among males [3]. The prevalence of infertility in the developed countries is estimated at $3.5-16.7 \%$ (mean 9\%), while the percentage of couples seeking medical assistance due to this reason is $42-76.3 \%$ (mean $56.1 \%$ ) [4].

\section{OBJECTIVE}

The objective of the study is systematization of the state of knowledge concerning nutritional conditioning of fertility, with consideration of the energy aspects of nutrition and the effect of dietary components on fertility, drawing attention to the possibilities of applying dietary interventions in supporting the treatment of fertility. The demand for a study of such a profile is justified by clinical experiences, indicating the use of pseudo-dietary therapies by patients treated due to infertility, which is associated with evoking hopes for obtaining pregnancy, which are not always justified. A constantly up-to-date challenge on the border

Address for correspondence: Michal Skrzypek, Department of Clinical Dietetics, Faculty of Health Sciences, Medical University, Lublin, Poland e-mail: michal.skrzypek@umlub.pl

Received: 05.06.2017; accepted: 15.09.2017; first published: 24.10.2017 between reproductive medicine and dietetics remains the determination of the assumptions of a pre-conception diet, with confirmed within the paradigm EBM (evidence-based medicine) potential for supporting fertility (fertility diet), as well as defining the principles of dietary management in supporting infertility treatment, including by the IVF (in vitro fertilisation) method. Methodological difficulties will also be indicated in studies of the relationship between nutrition and fertility, which hinder the formulation of the recommendations for dietetic management in reproductive medicine [5].

Energy aspects of nutrition and fertility. In studies concerning the relationship between nutritional behaviours and body weight, and the reproductive health of females, attention is paid to the energy aspects of fertility, and the importance of macro- and micro-dietary components. Referring to the first of the mentioned problems, the attitude of Chavarro et al. should be quoted, who indicate that reproduction implies a significant energy expenditure, and the formation of female gametes requires for various species 3.5-times higher energy expenditure, compared to the male gametes [6]. The energy cost of pregnancy related with a normal foetal weight gain is estimated at 78,000 kcal. This explains the sense of evolutionary selection mechanism which has led to the formation of the reproductive system reacting to energy deficit by the suppression of reproductive functions [6]. Clinically, this is manifested by the occurrence of secondary amenorhea, and infertility in women with malnutrition [7]. This problem concerns the poorest countries, and in the western cultural cycle it is related with eating disorders and the undertaking by women of very intensive physical activity or maintaining low body mass (BM) by means of special diets $[5,7]$.

The relationship between abnormal BM and the fertility of women is of a bimodal character: both low values of the Body Mass Index $(\mathrm{BMI}<19)$ and the values indicating overweight (25-29.9), imply the risk of infertility, with especially high 
infertility risk concerning obese women $(\mathrm{BMI}>30)[5]$. Too low BM in women implies anovulation, lack of menstruation, disorders of the hypothalamic-pituitary-ovarian axis, as well as a two-fold increase in the risk of infertility, compared to women with a normal BM. For this reason, women with BMI below 18.5 are recommended to obtain normal BM before undertaking conception attempts [2]. The issue of the effect of malnutrition and low BMI index on the effectiveness of IVF has not been fully recognized [8]. A more comprehensive analysis of reproductive implications of malnutrition will be omitted here, because this is not a widely prevalent problem in the populations of developed countries, and focus will be placed on the problem of the relationship between excessive $\mathrm{BM}$ and fertility. Ovulation disorders are considered as a dominant pathophysiological mechanism of infertility in obese women $[5,6]$. In the programme Nurses' Health Study II a linear relationship was confirmed between infertility risk caused by ovulation disorders and the BMI value. Women aged 18 with BMI $>22$ showed a higher risk of ovulation infertility, compared to those within the range of BMI 20 - 21.9. A linear increase in the risk of ovulation infertility was found, up to the value of BMI $=30$, at which it was 2.7-times higher (from this value the risk did not increase). The researchers concluded that each increase in the BMI index, already from the value of 23 at the age of 18, may be considered as a risk factor of ovulation infertility at an older age [9]. In women who ovulate, each increase in BMI by one unit within the range of values above 29 results in a decrease in the chances for spontaneous conception by $5 \%$ [5]. However, when in the situation of application of assisted reproductive technologies in obese women, the chance for obtaining pregnancy is lower than in women with normal $\mathrm{BM}[10,11,12]$. El-Toukhky et al. concluded that, based on the review of 152 literature reports, obesity is related with a 3 -fold increase in the risk of infertility in females, as well as the reduction of chances for successful IVF treatment [2]. The mechanisms which lead to the occurrence of infertility in obese women are associated with ovulation disorders, and also with the phenomenon of oxygen shock, changes in the levels of adipocytokines, endothelial dysfunction, markers of inflammatory state, problems related with intercourse, increased risk of miscarriage, as well as complications in the course of later stages of pregnancy.

Considering the first of the mechanisms mentioned, it should be added that ovulation disorders in obese women may be conditioned by the PCOS (polycystic ovary syndrome), which is related with the occurrence of overweight and obesity, and abnormal glucose tolerance [13]. In the case of obese women with PCOS, menstrual cycles are prolonged and often anovulatory. The thickened shell of the polycystic ovary may favour the occurrence of problems with the breaking open of the ovarian follicle, which additionally decreases the chance for obtaining pregnancy during natural attempts. In women with PCOS who receive the IVF procedure, the obtained embryos are of lower quality $[14,15]$, and each stimulation of ovulation in women with PCOS increases the risk of occurrence of the ovarian hyperstimulation syndrome, which may lead to a life threatening state [16]. Referring to the etiopathogenesis of infertility in women with PCOS, Chavarro et al. ascribed priority importance to the disorders of carbohydrate metabolism and insulin resistance as the factors affecting ovulation. This thesis is supported by the results of studies indicating the beneficial effect of anti- diabetic treatment in the course of PCOS on ovarian function and improving fertility [6]. Such an effect was obtained by Kjotrod et al. in a randomized clinical trial which covered a group of women with PCOS without obesity, in whom the administration of metformin at a dose of 2,000 mg during the period of 12 weeks preceding IVF or ICSI (intracytoplasmic sperm injection), was related with a higher chance for obtaining pregnancy. In the group receiving metformin, $50 \%$ of clinically confirmed pregnancies were noted, whereas in the group receiving placebo $-33.3 \%$. Live births were noted in $48.6 \%$ of the women who received metformin, while among those who received placebo $-32 \%$. The researchers emphasized that the clinical outcome resulted from increasing the chance for spontaneous pregnancy in the group receiving metformin, and was not the effect of the improvement of the effectiveness of IVF [17]. It was also confirmed that the reduction of body weight in women with PCOS, leading to reduction in insulin resistance, increased the chance for regaining spontaneous ovulatory function or improvement of the response to the stimulation of the ovaries [18]. Moran et al. showed that reduction of the body mass in women with PCOS with overweight, followed by implementation of a 6-month dietary programme supporting the obtained effect of $\mathrm{BM}$ reduction, considerably improved the metabolic profile (decrease in the level of insulin, reduction of the content of fat in the body) and hormonal profile, including the reduction of the level of T (testosterone) and FAI (free androgen index), and also in a part of the examined women (57.1\%) restored/ stabilized the regularity of the menstrual cycle [19]. Thus, an improvement of the reproductive functions in women with PCOS may be obtained by undertaking insulin-sensitizing actions, both dietary and pharmacological (e.g. treatment with metformin); however, with the reservation that, while designing dietary interventions in obese women, one should strive for a moderate and not intensive physical activity, because in such a case there may occur an additional adverse effect of the reduction of fertility, independent of the changes in the content of fatty tissue in the body [20].

Chavarro et al. presented an opinion that the effect of disorders of carbohydrate homeostasis and insulin resistance on ovulatory function concerns also infertile women without PCOS, and may be considered as a universal mechanism explaining a coherent relationship between obesity and ovulation disorders confirmed in a number of studies [6]. However, while explaining pathophysiology of fertility disorders in obese women, a relatively smaller importance is ascribed to other mechanisms, among which is mentioned the role of the environment of the maturation of the ovum, which exerts a direct effect on the quality of the oocyte, quality of the embryo, and the chance to obtain pregnancy. Fatty tissue collected in the body contributes to an increase in the phenomenon of oxidative stress by production of an excess of adipocytokines and reactive oxygen species, which in the follicular fluid negatively affect the maturating oocyte $[21,22,23]$. Also, mitochondrial dysfunction related with obesity contributes to the occurrence of oxygen shock [24]. Bausenwein et al. confirmed that changes in the activity of oxLDL (oxidized low-density lipoprotein) and catalase in obese women also contribute to a decrease in fertility.

The above-quoted researchers analyzed changes in the activity of SOD (super-oxide dismutase), glutathione peroxidase, glutathione reductase, oxLDL, and catalase in the follicular fluid and plasma of patients treated using 
the IVF method. The patients were divided into 3 groups: those obese with PCOS, obese without PCOS, and women with normal body weight, without PCOS. A higher oxLDL and catalase activity was observed on a similar level in both groups of obese patients, and was higher than in the remainder, which suggests the lack of effect of PCOS on the occurrence of oxygen shock, at the same time, paying attention to the greater importance of obesity as such in generating this phenomenon. Bausenwein et al. speculated that the described relationships may be the cause of disorders in the maturation of the egg cells and, consequently, a lower percentage of pregnancies obtained after IVF in the group of obese women (19.5\%), compared to the remainder (38.5\%) [12]. Different results were obtained by Seleem et al. who showed that in patients with PCOS a decrease is observed in the SOD activity, compared to women without PCOS; nevertheless, this does not exert an effect on either the quality of the embryos, or the therapeutic outcome in the form of pregnancy obtained [25]. El-Toukhky et al., while summing up the state of knowledge concerning pathophysiological mechanisms explaining the relationship between obesity in women and infertility, drew attention to the hypothalamicpituitary axis dysfunction in this group of patients, caused by the peripheral aromatization of androgens into estrogens, as well as insulin resistance which, in combination with hyperglycaemia and hyperinsulinaemia and the effect of proinflammatory cytokines and an increased concentration of insulin in the ovarian follicles in obese women, leads to disorders in the development of oocytes and results in anovulation, immaturity of oocytes, and their decreased quality, implying fertility disorders and difficulties in the treatment of obese women by the IVF method [2].

The effect of abnormally high BM on the course of pregnancy implies specific therapeutic recommendations. Since 1 June 2016 in Poland, the regulation by the Minister of Health imposes on the staff providing obstetric care of a pregnant woman with $\mathrm{BMI}>30$ the obligation to introduce prophylaxis of preeclampsia, consisting in the supplementation of acetylsalicylic acid prior to week 16 of pregnancy. The same regulation recommends in patients with BMI $>35$, within prevention of postpartum haemorrhage prophylaxis of obstetric haemorrhage in the third stage of labour, the replacement of short-acting oxytocin by its long-acting analogue (carbetocin), or other equally strong uterotonic [26].

The relationship between BM and fertility in males is not as strong as in females, and scientific evidence concerning this issue is not consistent [27]. Hammoud et al. [28] indicated that, both in the general population and in the population of infertile couples, obesity is related with a decreased fertility in males; however, this researcher evaluated the effect of obesity on males fertility as moderate. Chavarro et al., in a cross-sectional study in a group of 483 males, showed that only a considerable intensification of obesity $(B M I \geq 35)$ was associated with a worse total sperm count than in healthy males. Nevertheless, the BMI index within the values below 35 was not related with the number of sperm, their motility, nor with morphology [29]. Sermondade et al., based on a population study, concluded that the presence of a dose-response relationship may be presumed between BMI and male subfertility, understood as a prolonged time to conception of more than 12 months, with the plateau effect above the value of BMI 32-35 [3]. According to the above-quoted researchers, obesity affects male fertility primarily by modification of the overall sperm concentration in the ejaculate, while it affects neither sperm motility nor morphology [3]. Here, a study should also be quoted which differs from such a conclusion. Kort et al. indicated an opposite, statistically significant relationship between the value of BMI index and sperm motility, as well as an index of chromatin integration in sperm, evaluated by the DFI (DNA fragmentation index), where males with $\mathrm{BMI}>25$, compared to those with normal body weight, were characterized by a lower content of chromatin-intact normal-motile sperm cells in the ejaculate [30]. Referring to this problem, Sermondade et al. reported that in the majority of studies completed in 2015 , a significant relationship was found between the BMI value and sperm DNA fragmentation, which may explain difficulties with the performance of IVF in the partners of obese men, consisting in a decrease in the implantation potential of embryos, and problems with obtaining a good quality embryo [3]. Considering the above-presented observations it should be added that the sperm have no mechanisms for DNA repair, and the potential chromatin damage is repaired by the oocyte.

Pathophysiological mechanisms explaining the relationship between overweight and obesity, and fertility disorders in males have been the object of many studies in which attention is paid to the change in hormonal profile, including a decrease in total and free T, FSH (follicle-stimulating hormone) and $\mathrm{LH}$ (luteinizing hormone), and an increase in the levels of estradiol and estrone, as a result of aromatization of androgens into estrogens in the adipose tissue. Estrogens, by exerting an effect on the hypothalamus and the pituitary gland, disturb $\mathrm{T}$ synthesis in the testes [3]. In a number of studies, the effect was analyzed of endocrine activity of adipose tissue on fertility, drawing attention to the role of adipokines synthetized in the adipose tissue. Among others, the central effect of grelin on the pituitary gland was confirmed, which decreases the secretion of FSH and $\mathrm{LH}$ [31], as well as the effect of adiponectin, decreasing the secretion of $\mathrm{LH}$ and resistin, which affects adiponectin receptors expression [3]. In obese males, a higher risk of erection disturbances is also observed, related with damage to the cardiovascular system as a result of obesity-related glucometabolic and lipid disorders.

Dietry macrocomponents and fertility. The state of knowledge concerning the effect of dietary macrocomponents on female fertility seems to be coherent with generally adopted guidelines for health-promoting nutrition [32], where the common goal of nutritional prevention of NCD's (non-communicable chronic diseases) and infertility in women is striving at avoidance/reduction of insulin resistance, hyperinsulinaemia and hyperglycaemia, this principle concerning both women with the diagnosis of PCOS, and those without PCOS. It has been proved that dietary interventions biased towards an improvement in insulin sensitivity bring about benefit with respect to the improvement of fertility, especially in women. Considering the consumption of FA (fatty acids) a beneficial effect of the consumption of MUFA (monunsaturated fatty acids) or PUFA (polyunsaturated fatty acids) was demonstrated as an alternative for SFA (saturated fatty acids) on female fertility [33], which is in accordance with the latest recommendations for nutrition in the prevention of coronary disease - ESC 2016 (European Society of Cardiology) [34]. 
The consumption of TFA (trans fatty acids) exerts a negative effect on fertility, because TFA induce insulin resistance [33]. In the Nurses' Health Study II it was confirmed that an increase by $2 \%$ of energy obtained from TFA at the cost of energy from carbohydrates results in an increase in the risk of ovulatory infertility by $73 \%$, after consideration of other known factors influencing this effect [33]. However, in the light of presently available data, it is not possible to formulate unequivocal recommendations concerning the portions of energy obtained from individual fractions of fatty acids, which would be optimum in supporting fertility. It is also not completely clear whether MUFA or PUFA are the best alternative for energy obtained from SFA within a fertility diet. Phelan et al. prove that, based on a randomized experiment, supplementation with PUFA from n-3 group in females with PCOS (2.4 g n-3 LC PUFA) (long chain polyunsaturated fatty acids) brings about the desired metabolic and hormonal changes, including the reduction of the $\mathrm{T}$ concentration in blood plasma [35]. Attention is also paid to the beneficial effect of LC-PUFA supporting the effectiveness of IVF, both with respect to the morphology of the embryo, and an increase in the chances for pregnancy. However, according to Zander-Fox et al., considering the negative consequences of supplementation of LC-PUFA for the development of embryos as confirmed by studies on animals, further research is necessary concerning this problem [8]. Zander-Fox et al. do not recommend the use of fish oil as a supplementation of n-3 PUFA in the course of IVF treatment, arguing that this may cause a decreased response to IVF stimulation, and also result in disorders in the quality of the oocyte and embryo, and an increase in the risk of perioperative bleedings as a result of antithrombotic effect [8].

With respect to the consumption of carbohydrates, it has been shown that an excessive supply of energy from this source, as well as the type of the carbohydrates consumed, may impact insulin sensitivity and may lead to an increase in the ovulatory infertility. An 8-year prospective study by Chavarro et al., conducted in a group of 18,555 healthy women at reproductive age, without the diagnosis of infertility, showed that the level of consumption of carbohydrates, as well as the dietary glycaemic load are significantly related with the risk of ovulatory infertility. Women who remain in the highest quintile of dietary glycaemic load showed a by $92 \%$ higher risk of this disorder, compared to those in the lowest quintile. Researchers from Harvard suggest that both the amount and the type of carbohydrates consumed affect the course of ovulation and condition fertility in women [36]. Also, studies in women with PCOS support these observations. Douglas et al. [37] found that the application of an eucaloric diet, with a decreased content of carbohydrates, where energy from carbohydrates is replaced by energy from PUFA, leads to a decrease in the level of insulin in women with PCOS and favours an improvement in reproductive functions.

Concerning the importance of the source of proteins (plant vs. animal) as a modulator for fertility, in the study by Chavarro et al. it was observed that the consumption of animal proteins favours ovulatory infertility, whereas the consumption of plant proteins seems to have a protective effect. The researchers from Harvard report that the modification of nutrition leading to the obtaining of $5 \%$ of energy from plant proteins instead of animal proteins, decreases the risk of ovulatory infertility by a half [38]. It is noteworthy that red meat, as a source of animal proteins and SFA, does not favour fertility. This refers, among others, to the effect of residual presence of anabolic hormones, applied in cattle in order to support growth within the period of 60-90 days before slaughter in the USA, Canada, and other countries from outside the EU (in the EU such actions are prohibited) [6].

Discussion of the importance of dietary microcomponents in the prevention and treatment of infertility requires a separate study. Zander-Fox et al. indicate that considering the methodological and statistical limitations of many studies in this area, the formulation of evidence-based recommendations is highly problematic, and the use of multicomponent vitamin supplements in supporting infertility treatment requires further studies which would precisely determine which particular components of such preparations provide the best benefits, and what their optimum formula should be [8].

Dietary interventions in prophylaxis and treatment of infertility - Towards a fertility diet? The inspiration for seeking an optimum formula for a fertility diet are reports suggesting that the negative effect of disorders in the state of nutrition on fertility is reversible in some cases. Correction of the negative energy balance in the situation of malnutrition leads to the improvement of fertility. Wabitsch et al. found that in males with anorexia, dietary intervention led to a significant increase in the level of leptin, considered as a causative agent of the hypothalamic pituitary gonadal axis disorders, which is accompanied by an increase in the levels of gonadotropin (LH, FSH), T, and an increase in FAI index (free androgen index), where leptin concentrations in blood plasma were positively correlated with T levels, and the values of FAI index (the limitation of the study was that the observation was conducted in only 3 males) [39]. In turn, considering the reproductive effects of abnormally high $\mathrm{BM}$, it should be emphasized that even a relatively small, $5 \%$ reduction of $\mathrm{BM}$ among obese women, may result in the restoration of ovulation and regular menstrual cycles, as well as an increase in the chances for conception [2]. Within prevention of infertility during the pre-conception period in obese women, a slow reduction of BM is recommended by means of dietary intervention and physical activity, screening for diabetes, as well as the supplementation of folic acid at a dose increased up to $5 \mathrm{mg}$, due to the relatively higher deficiency of this vitamin in women with high BMI [2]; nevertheless, the reduction of body weight should be approached as first-line therapy [40]. However, radical dietary management resulting in a rapid loss of BM, including the application of VLCD (very-low calorie diet), is not recommended because such management may disturb the developmental environment of the oocytes (ketosis, hormonal homeostasis), and lead to a decrease in the quality of oocytes and embryos, resulting in the chances for treatment using the ART methods (assisted reproductive technology) being reduced [8]. Considering difficulties in the treatment of fertility in obese women, the British Fertility Society recommends not undertaking treatment until the moment of reducing BMI to below 35, with an indication of an optimum value of BMI below 30 [40]. Also, in the case of abnormally high BM in males, the available data suggest a beneficial effect of the reduction of $\mathrm{BM}$ on $\mathrm{T}$ levels in blood plasma and sperm parameters, even if the complete normalization of BM is not obtained. Nevertheless, the 
quality of the data concerning this issue is relatively low, because the majority of them are of the character of a series of cases, with a lack of randomized experimental studies [3].

While discussing the implications of the state of research concerning nutritional conditioning of fertility for dietary management in reproductive medicine, attention should be paid to the methodological difficulties associated with conducting studies of such a profile. The basic difficulty is that although many dietary factors have been indicated which disturb fertility, the overall effect of the mode of nutrition does not have to reflect the influences of individual food components on fertility reported in the studies, due to the synergistic effect of simultaneously consumed dietary components. Difficulties also occur in the recruitment of the participants of prospective studies of the elements of life style, including the mode of nutrition on fertility [5], as well as those concerning blinding in randomized studies (how to differentiate the mode of nutrition in the control arm, and that testing the evaluated intervention, while maintaining the identical appearance and taste of the meals served to the study participants). Due to these difficulties, there is relatively little scientific evidence concerning the effect of nutrition on fertility from RCT (randomized controlled trials). Therefore, as early as 2007 , Lim et al. suggested that there is no reliable scientific evidence indicating that dietary interventions support infertility treatment [41]. However, the observation studies available suggest a significant potential of dietary interventions in reproductive medicine. Chavarro et al, based on an 8-year prospective observation of 17,544 women without the diagnosis of infertility, showed that the mode of nutrition characterized by, among others, a high consumption of MUFA, low TFA, high consumption of plant proteins, and low consumption of animals proteins, consumption of carbohydrates with a low glycaemic index, and the use of multi-vitamin preparations, as well as the consumption of low fat dairy products, protects against the occurrence of ovulatory infertility and, to a lesser degree, infertility through other causes. The combination of factors which are elements of life style, with consideration of the mode of nutrition, maintenance of a normal BM and physical activity, was related with a lower by $69 \%$ risk of ovulatory infertility (95\% CI 29-86\%). The researchers estimated that in a half of the cases of ovulatory infertility, it may be prevented by modification of the mode of nutrition, and expansion of these actions by the control of BM. Furthermore, physical activity enables the prevention of $2 / 3$ cases of infertility $[42,43]$.

The results of the programme concerning the role of low fat dairy products as a protective factor for ovulatory infertility require comment. This relationship is explained by the fact that low fat dairy products increased the level of the IGF-i factor (insulin-like growth factor), related with the pathogenesis of PCOS [6]. Also, a Spanish study by Toledo et al. [44] indicated that the model of the Mediterranean diet, compared to the western mode of nutrition, is characterized by a considerable potential for supporting fertility. In turn, Vujkovic et al. [45] found that the application of a diet equivalent to the model Mediterranean diet in supporting treatment by the IVF/ICSI method (intracytoplasmic sperm injection) is conducive to the achievement of therapeutic success.

A basic and documented pathophysiological mechanism explaining the nutritional conditioning of female infertility concerns the effect of energy and dietary macrocomponents balance on the risk of insulin resistance related with hyperinsulinaemia, which has a strong potential for disturbing ovulation. Other mechanisms are not equally strongly grounded in the state of research. It should be emphasized that the pathogenic effect concerns both extreme situations of energy balance: an extremely low BMI (below 18), as well as a high BMI (in the population with PCOS and without such a diagnosis), implies ovulatory infertility, while the correction of the disorders in the state of nutrition increases chances for the restoration of ovarian function. With respect to the role of dietary macrocomponents in the modelling of female fertility, summing-up the state of research, Chavarro [6] concluded that the role of consumption of SFA, TFA and carbohydrates with high glycaemic index as risk factors of ovulatory infertility (mediated by the risk of insulin resistance), may be considered as confirmed, whereas the findings concerning the role of plant vs. animal proteins, as well as dietary fibre, are inconclusive. In turn, into the dietary microcomponents with a proven effect on female fertility, Chavarro [6] classifies folic acid, the deficits of which were related with ovulation disorders and a low level of progesterone in the luteal phase; it is probable that vitamin $\mathrm{D}$ is of such an importance (in studies on animals and in women with PCOS related with ovulation disorders), and also non-heme iron of plant origin, characterized by a proven potential for reducing the risk of ovulatory infertility.

Summing-up the state of research concerning the effect of energy balance disorders on male fertility, Sermondade et al. [3] concluded that in the light of the majority of studies, it may be presumed that overweight and obesity exert a negative effect on the overall sperm concentration, while there is no consistent evidence for the effect on sperm motility and morphology. The majority of clinical studies also indicate a relationship between BMI and sperm DNA fragmentation, which may explain the lower quality of embryos in the IVF procedure in the situation when an obese male is the donor [3]. The pathophysiological background of fertility disorders in obese males is associated with HP disorder (hypothalamic-pituitary axis) and the function of Leydig cells in the testes, these mechanisms being related with, among others, the effects of peripheral aromatization of androgens into estrogens in the adipose tissue. There is no evidence from experimental trials documenting the effect of the reduction of BM on the improvement of fertility in males; however, the results of observation studies seem to indicate such benefits. Sermondade et al. [3] presented an opinion that the reduction of $\mathrm{BM}$ on the route of dietary interventions and physical activity may be approached as the first-line fertility treatment in obese males. It should be noted that there is no evidence for the effect of male malnutrition on sperm parameters [3].

Considering the effect of individual dietary elements on male fertility, Afeiche et al. [46], based on the analysis of 219 literature reports, considered as confirmed: the beneficial effect of low fat dairy products, unsaturated FA and folic acid, while an adverse effect on sperm parameters exerted by consumption of processed red meat, high fat dairy products, SFA, TFA, excess of alcohol and soy products (containing isoflavones characterized by estrogen-like activity); these dietary components negatively affecting primarily sperm morphology and motility. It is presumed that this effect depends on the effect of SFA, residual content of estrogens in dairy products and meat of agents used for the preservation of meat [46]. Afeiche et al. considered 
as inconclusive the observations concerning the role of antioxidants in supporting male fertility used in the form of dietary supplements, due to insufficient data concerning their effect on live births or clinical pregnancies among couples treated for infertility [46]. A different opinion was presented in a meta-analysis by Showella et al. in 2011 [47] which covered 34 studies of the RCT type, and suggested that the supplementation of antioxidants in subfertile males may improve the effectiveness of treatment by the ART techniques evaluated with the consideration of live births or pregnancies. However, there is no doubt that a high consumption of fruits and vegetables providing the supply of antioxidants in a natural form, favour the maintenance of the optimum sperm parameters [46].

Attention is also paid to the role of folic acid as a factor improving sperm count and motility, and reducing DNA fragmentation, as well as the role of vitamin D having a similar effect on sperm; however, in this case, there is no evidence from RCT [46]. In the majority of studies on the effect of caffeine on sperm parameters, its negative effect was not confirmed, similar to the moderate consumption of alcohol, with the reservation, however, that a high consumption (above 20 standard units weekly) negatively affects the hormonal profile in males, increasing the level of estrogens, and reducing $\mathrm{T}$ [46]. Despite important methodological limitations in the studies indicating dietary determinants of male infertility, consisting in the fact that the studies are most frequently conducted in populations of subfertile males who have most often performed health promoting changes in their life style in association with the disease, not representative for the population of fertile males, Afeiche et al. proposed a nutritional pattern supporting male fertility, considering a high amount of fruit and vegetables, fish and nuts (due to n-3), a moderate amount of alcohol with a simultaneous reduction in the consumption of red meat (especially processed meat), high fat dairy products, hydrogenated fat (due to TFA) and soy products, in combination with moderate physical effort; however, not of a high-performance character [46].

\section{CONCLUSIONS}

Despite a deficit of the highest quality scientific evidence concerning the effect of nutrition on fertility obtained in RCT, which is now based mostly on the analysis of the available data from observation studies, it may be concluded that it is justifiable to approach professional dietary interventions as an integral element in the primary prevention and treatment of infertility.

\section{REFERENCES}

1. http://www.who.int/mediacentre/factsheets/fs311/en/ dostęp z dnia 20.04.2017 r.

2. El-Toukhy T, Osman A. Macronutrient intake, fertility, and pregnancy outcome. In: "Nutrition, Fertility, and Human Reproductive Function", Kelton Tremellen, Karma Pearce (eds.), CRC Press 2015: 51-67.

3. Sermondade N, Dupont Ch, Faure C, Levy R. The effect of obesity on male reproductive function, In: "Nutrition, Fertility, and Human Reproductive Function”, Kelton Tremellen, Karma Pearce (eds.), CRC Press 2015: 192-211.

4. Boivin J, Bunting L, Collins JA, Nygren KG. International estimates of infertility prevalence and treatment-seeking: potential need and demand for infertility medical care. Hum Reprod. 2007; 22: 1506-1512.
5. Fontana R, Della Torre S. The deep correlation between energy metabolism and reproduction: A view on the effects of nutrition for women fertility. Nutrients 2016; 8(87): 1-34.

6. Chavarro JE, Gaskins AJ, Afeiche BM. Nutrition and the ovulatory function. In: "Nutrition, Fertility, and Human Reproductive Function", Kelton Tremellen, Karma Pearce (eds.), CRC Press 2015: 1-26.

7. Frisch RE. Body fat, menarche, fitness and fertility. Hum Reprod. 1987; 2(6): 521-533.

8. Zander-Fox D, Bakos HW. The role of nutrition in optimizing assisted reproductive technology treatment outcomes. In: "Nutrition, Fertility, and Human Reproductive Function”, Kelton Tremellen, Karma Pearce (eds.), CRC Press 2015: 283-308.

9. Rich-Edwards JW, Goldman MB, Willett WC, Hunter DJ, Stampfer MJ, Colditz GA et al. Adolescent body mass index and infertility caused by ovulatory disorder. Am J Obstet Gynecol. 1994; 171(1): 171-177.

10. Fedorcsák P, Dale PO, Storeng R, Tanbo T, Abyholm T. The impact of obesity and insulin resistance on the outcome of IVF or ICSI in women with polycystic ovarian syndrome. Hum Reprod. 2001; 16(6): 1086-1091.

11. Wang JX, Davies M, Norman RJ. Body mass and probability of pregnancy during assisted reproduction treatment: retrospective study. BMJ. 2000; 321(7272): 1320-1321.

12. Bausenwein J, Serke H, Eberle K, Hirrlinger J, Jogschies P et al. Elevated levels of oxidized low-density lipoprotein and of catalase activity in follicular fluid of obese women. Mol Hum Reprod. 2010; 16: 117-24.

13. Vitek W, Hoeger K, Legro RS. Treatment strategies for infertile women with polycystic ovary syndrome. Minerva Ginecol. 2016; 68(4): 450-457.

14. Gu BX, Wang X, Yin BL, Guo HB, Zhang HL, Zhang SD, et al. Abnormal expression of TLRs may play a role in lower embryo quality of women with polycystic ovary syndrome. Syst Biol Reprod Med. 2016; 1: 1-6.

15. Liu Z, Liu C, Hao C, Xue Q, Huang X, Zhang N, et al. Aberrant expression of angiopoietin-like proteins 1 and 2 in cumulus cells is potentially associated with impaired oocyte developmental competence in polycystic ovary syndrome. Gynecol Endocrinol. 2016; 1: 1-5.

16. Fischer D, Reisenbüchler C, Rösner S, Haussmann J, Wimberger P, Goeckenjan M. Avoiding OHSS: Controlled Ovarian Low-Dose Stimulation in Women with PCOS. Geburtshilfe Frauenheilkd. 2016; 76(6): 718-726.

17. Kjotrod SB, Carlsen SM, Rasmussen PE, Holst-Larsen T, Mellembakken J, Thurin-Kjellberg A, et al. Use of metformin before and during assisted reproductive technology in non-obese young infertile women with polycystic ovary syndrome: a prospective, randomized, double-blind, multi-centre study. Hum Reprod. 2011; 26(8): 2045-2053.

18. Norman RJ, Noakes M, Wu R, Davies MJ, Moran L, Wang JX. Improving reproductive performance in overweight/obese women with effective weight management. Hum Reprod. Update 2004; 10(3): 267-280.

19. Moran L, Noakes M, Clifton PM, Wittert GA, Williams G, Norman RJ. Short-term meal replacements followed by dietary macronutrient restriction enhance weight loss in polycystic ovary syndrome. Am J Clin Nutr. 2006; 84: 77-87.

20. Gudmundsdottir SL, Flanders WD, Augestad LB. Menstrual Cycle Abnormalities in HealthyWomen With Low Physical Activity: The North-Trondelag Population-based Health Study. J. Phys. Act. Health 2014; 11: 1133-1140.

21. Opuwari CS, Henkel RR. An Update on Oxidative Damage to Spermatozoa and Oocytes. Biomed Res Int. 2016; 2016: 9540142.

22. Kuzmenko DI, Udintsev SN, Klimentyeva TK, Serebrov VY. Oxidative stress in adipose tissue as a primary link in pathogenesis of insulin resistance. Biomed Khim. 2016; 62(1): 14-21.

23. Wdowiak A. Comparing antioxidant enzyme levels in follicular fluid in ICSI-treated patients. Gynecol Obstet Fertil. 2015; 43(7-8): 515-521.

24. Koliaki C, Roden M. Alterations of Mitochondrial Function and Insulin Sensitivity in Human Obesity and Diabetes Mellitus. Annu Rev Nutr. 2016 May 4. [Epub ahead of print]

25. Seleem AK, El Refaeey AA, Shaalan D, Sherbiny Y, Badawy A. Superoxide dismutase in polycystic ovary syndrome patients undergoing intracytoplasmic sperm injection. J Assist Reprod Genet. 2014; 31(4): 499-504.

26. DZIENNIK USTAW RZECZYPOSPOLITEJ POLSKIEJ, Warszawa, dnia 1 grudnia 2015 r., Poz. 2007, ROZPORZĄDZENIE MINISTRA ZDROWIA z dnia 9 listopada 2015 r. w sprawie standardów postępowania medycznego przy udzielaniu świadczeń zdrowotnych w dziedzinie położnictwa i ginekologii z zakresu okołoporodowej opieki położniczo-ginekologicznej, sprawowanej nad kobietą w okresie ciąży, porodu, połogu, w przypadkach występowania określonych powikłań oraz opieki nad kobietą w sytuacji niepowodzeń położniczych. 
27. Szkodziak P, Wozniak S, Czuczwar P, Wozniakowska E, Milart P Mroczkowski A, Paszkowski T. Infertility in the light of new scientific reports - focus on male factor. Ann Agric Environ Med. 2016; 23(2): 227-230.

28. Hammoud AO, Gibson M, Peterson M, Meikle AW, Carrel DT. Impact of male obesity on infertility: a critical review of the current literature. Fertil Steril. 2008; 90(4): 897-904.

29. Chavarro JE, Toth TL, Wright DL, Meeker JD, Hauser R. Body mass index in relation to semen quality, sperm DNA integrity, and serum reproductive hormone levels among men attending an infertility clinic. Fertil Steril. 2010; 93: 2222-2231.

30. Kort HI, Massey JB, Elsner CW, Mitchell-Leef D, Shapiro DB, Witt MA et al. Impact of body mass index values on sperm quantity and quality. J Androl. 2006; 27(3): 450-452.

31. Tena-Sempere M. Roles of ghrelin and leptin in the control of reproductive function. Neuroendocrinology 2007; 86(3): 229-241.

32. Lee RD, Nieman DC. Standards for Nutrient Intake. In: Nutritional Assessment. Sixth Edition. The McGraw-Hill Companies, New York, USA. 2013: 21-73.

33. Chavarro JE, Rich-Edwards JW. i wsp. Dietary fatty acids intakes and the risk of ovulatory infertility. Am J Clin Nutr. 2007; 85(1): 231-237.

34. 2016 European Guidelines on cardiovascular disease prevention in clinical practice The Sixth Joint Task Force of the European Society of Cardiology and Other Societies on Cardiovascular Disease Prevention in Clinical Practice (constituted by representatives of 10 societies and by invited experts). Eur J Preventive Cardiol. 2016; 23(11): 1-96.

35. Phelan N, O'Connor A, Kyaw Tun T, Correia N, Boran G, Roche HM, et al. Hormonal and metabolic effects of polyunsaturated fatty acids in young women with polycystic ovary syndrome: results from a crosssectional analysis and a randomized, placebo-controlled, crossover trial. Am J Clin Nutr. 2011; 93: 652-662.

36. Chavarro JE, Rich-Edwards JW, Rosner BA, Willett WC. A prospective study of dietary carbohydrate quantity and quality in relation to risk of ovulatory infertility. Eur J Clin Nutr. 2009; 63: 78-86.
37. Douglas CC, Gower BA, Darnell BE, Ovalle F, Oster RA, Azziz R. Role of diet in the treatment of polycystic ovary syndrome. Fertil Steril. 2006; 85: 679-688.

38. Chavarro JE, Rich-Edwards JW, Rosner BA, Willett WC. Protein intake and ovulatory infertility. Am J Obstet Gynecol. 2008; 198(2): 210. e1-210.e7.

39. Wabitsch M, Ballauff FH, Holl R, Blum WF, Heinze E, Remschmidt $\mathrm{H}$, et al. Serum leptin, gonadotropin, and testosterone concentrations in male patients with anorexia nervosa during weight gain. J Clin Endocrionol Metab. 2001; 86(7): 2982-2988.

40. Brewer CJ, Balen A. The adverse effects of obesity on conception and implantation. Reproduction 2010; 140(3): 347-364.

41. Lim SS, Noakes M, Norman RJ. Dietary effects on fertility treatment and pregnancy outcomes. Curr Opinion Endocrinol Diabetes Obes. 2007; 14: 465-469.

42. Chavarro JE, Rich-Edwards JW, Rosner BA, Willett WC. Diet and lifestyle in the prevention of ovulatory disorder infertility. Obstet Gynecol. 2007; 110(5): 1050-1058.

43. Chavarro JE, Rich-Edwards JW, Rosner BA, Willett WC. A prospective study of dairy foods intake and anovulatory infertility. Hum Reprod. 2007; 22(5): 1340-1347.

44. Toledo E, Lopez-del Burgo C, Ruiz-Zambrana A, Donazar M, NavarroBlasco I, Martinez-Gonzalez M et al. Dietary patterns and difficulty onceiving: a nested case-control study, Fertil Steril. 2011; 96(5): 11491153.

45. Vujkovic M, de Vries JH, Lindemans J, Macklon NS, van der Spek PJ, Steegers EA et al. The preconception Mediterranean dietary pattern in couples undergoing in vitro fertilization/intracytoplasmic sperm injection treatment increases the chance of pregnancy. Fertil Steril. 2010; 94: 2096-2101.

46. Afeiche BM, Gaskins AJ, Chavarro JE. Nutrition and sperm function, In: "Nutrition, Fertility, and Human Reproductive Function", Kelton Tremellen, Karma Pearce (eds.), CRC Press 2015: 213-234.

47. Showell MG, Brown J, Yazdani A, Stankiewicz MT, Hart RJ. Antioxidants for male subfertility. Cochrane Database Syst Rev. 2011; 1: CD007411. doi: 10.1002/14651858.CD007411.pub2. 